\title{
Techniques for Materials Microanalysis
}

\author{
C.R. Helms, Guest Editor
}

The science and technology of ultrasmall three-dimensional materials systems has been developing rapidly the last 20 years or so. Catalysts, coatings, composites, as well as electronic device structures - all rely on materials properties on an atomic scale. To develop such new materials and understand the chemical and physical properties that determine their unique behavior, we also require analytical tools with atomic level spatial resolution and at the same time the desired measurement capability. This need, along with extensive scientific interest in the fundamental chemical and physical properties of free surfaces, has led to the continued development of microanalytical chemical analysis techniques over the past 20 years. Most readers will be familiar with many of these techniques with acronyms such as AES, XPS, RBS, SIMS, ESCA, etc. This issue of the MRS BULLETIN will review some recent advances in the development of these techniques as well as introduce new techniques with significant advantages over the older ones.

As you can see from the thickness of this issue, it is difficult to cover the entire field in a finite amount of space. This led us to limit the discussion to those microanalytical tools which can easily be applied to the analysis of buried interface structures such as those found in semiconductor devices. With this in mind, the articles are divided into four major sections:

1. the use of high energy ion beams for materials characterization, covered in the first three articles;

2. techniques used to produce and analyze particles sputter ejected from a surface, covered in the next three articles;

3 . recent advances in $x$-ray photoelectron spectroscopy, in the following two articles; and

4. Auger electron spectroscopy, covered in the final two articles.

Of the commonly applied techniques for interface microanalysis, Rutherford backscattering spectrometry (RBS) is clearly the most quantitative and can also be applied to nearly nondestructive testing. The major weaknesses of RBS are its typically poor lateral resolution, poor sensitivity to light atoms in heavy substrates, inability to separate spectra from elements of nearly the same mass, and poor depth resolution (except for very thin layers). The fundamental principles underlying the technique are described in "Materials Analysis with High Energy Ion Beams Part I:
Rutherford Backscattering" by H.J. Gossmann and L.C. Feldman.

The second article by Gossman and Feldman discusses the use of RBS equipment to study crystalline perfection via high energy ion channeling and to study light atoms via particle induced $x$-ray emission (PIXE) or nuclear reaction analysis (NRA). The third article in this section discusses the use of elastic recoil detection (ERD) for analyzing light atoms. This article from the group at Utrecht shows that ERD is extremely useful in determining hydrogen concentration profiles in thin film structures.

If high energy ion scattering techniques are the most quantitative, secondary ion mass spectrometry (SIMS) analyses are the most sensitive. Instruments with lateral resolution down to $1 \mu \mathrm{m}$ are currently available, and depth resolutions below 50 $\AA$ can be obtained. The major drawback to SIMS analysis is poor quantitative analysis, especially near surfaces and interfaces. The state-of-the-art in SIMS analysis is discussed by W. Katz and J.G. Newman, who include an excellent comparison of the ion sources and mass spectrometers available for SIMS analysis.

In the last few years, considerable effort has been put into improving the quantitative capabilities of mass spectrometry of sputter-ejected surface species. Two approaches are described. U. Kaiser and J.C. Huneke discuss the use of plasma ionization of sputtered neutrals prior to mass spectrometric detection, referred to as SNMS (sputtered neutral mass spectrometry). J.B. Pallix, C.H. Becker, and N. Newman describe the use of nonresonant multiphoton ionization prior to ion detection, referred to as SALI (surface analysis by laser ionization).

SNMS and SALI cannot be used directly to determine chemical bonding. X-ray photoelectron spectroscopy (XPS), sometimes called ESCA (electron spectroscopy for chemical analysis), has the greatest utility for such studies. For surface analysis, XPS is quite nondestructive and exhibits a depth resolution of $25 \AA$ or better. Its drawbacks are a much poorer sensitivity than SIMS and a lateral resolution typically poorer than techniques employing charged excitation beams that can be easily focused. The fundamentals of XPS are discussed by F.J. Grunthaner, who has used extensive studies of the $\mathrm{Si}-\mathrm{SiO}_{2}$ interface system as a vehicle to describe the capabilities and limitations of the technique. Recent advances in small spot XPS (ESCA) are discussed by C. Bryson and R.E. Chaney. These advances allow lateral resolution of $\sim 100 \mu \mathrm{m}$ and provide excellent compatibility with ion sources, so that good depth resolution is now possible in XPS sputter profiling.

The last technique discussed, undoubtedly used the most the last 20 years, is Auger electron spectroscopy (AES). Its advantages include good lateral and depth resolution and the ability to determine chemical bonding. Its major disadvantage is poorer sensitivity than SIMS. The fundamental concepts underlying AES are described by C.C. Chang along with examples of how the state-of-the-art of the technique can be pushed for analysis of semiconductor device structures. Recent developments in high lateral resolution $(<1000 \AA)$ AES and composition mapping are examined by $R$. Browning.

I hope this collection of papers on various techniques for interface microanalysis will give you an appreciation of the capabilities and limitations of some of the more routinely used techniques (RBS, SIMS, XPS, and AES), as well as an appreciation of the advances that mitigate some of the limitations. One of the goals of research in techniques for materials microanalysis has been to develop the one technique that can perform all the desired analytical tasks. This goal as yet unmet requires, in many instances, applying more than one technique to a given problem. The excellent discussions of the techniques by the authors in this issue should give you the ability to determine which technique or combination of techniques will be most effective for a particular application.

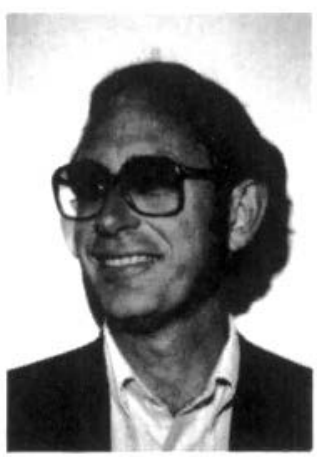

C. Robert Helms, guest editor for this issue of the MRS BULLETIN, is a professor of research in the Electrical Engineering Department at Stanford University. He received his BS from the University of California-Berkeley in 1968 and his PhD degree in electrical engineering from Stanford University in 1973. 
From 1973 through 1974, he was an IBM postdoctoral fellow at Stanford. In 1974 he joined EXXON Research and Engineering Company to pursue his interests in surface chemistry and catalytic properties of alloys. He returned to Stanford University in 1976 and received his present appointment in 1979. His current interests include semiconductor interface structures, interface analysis, and semiconductor materials processing. The major emphasis of this work is the relationship between electronic structure, chemical structure, and electrical properties of interfaces.

Helms has co-authored over 80 papers and has given 25 invited presentations at national meetings. He has been involved in various capacities such as program chairman or committee member at over 15 national meetings. He is a member of Phi Beta Kappa, Tau Beta Pi, the American Physical Society, American Vacuum Society, Electrochemical Society, and the Materials Research Society.

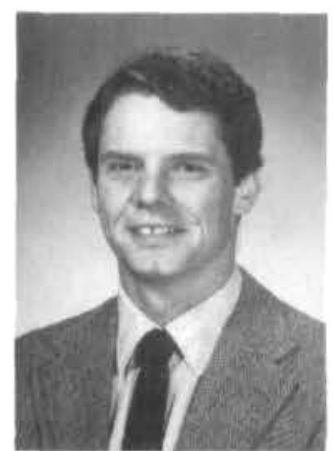

Christopher $\mathrm{H}$. Becker is a staff member in the Chemical Physics Laboratory of SRI International. He received his $\mathrm{PhD}$ in physical chemistry from the University of California at Berkeley in 1979. His research interests include surface and material chemical analysis using mass spectrometry, gas-surface interactions, and multiphoton ionization. An author or co-author of 30 technical publications, he is a member of American Physical Society, American Vacuum Society, American Chemical Society, and the Materials Research Society.

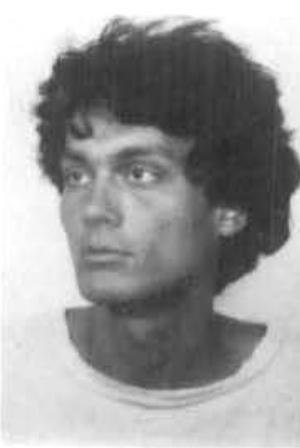

Wim Arnold Bik is presently in the final stages of his studies. His research has focused on the characterization of silicon oxynitrides and $\mathrm{Al}_{x} \mathrm{Ga}_{1-x} \mathrm{As}$, and on profiling of the SiNx/a-Si interface.

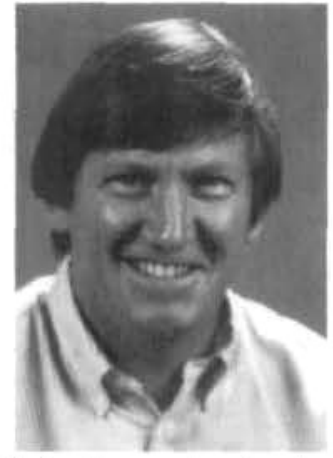

Raymond Browni n $\mathbf{B}$, s e $n$ i or research associate at the Center for Integrated Systems, Stanford University, is a physicist specializing in surface analytic techniques for use in materials science. He re. ceived his bachelor's degree in physics from London University and his D.Phil. from Sussex University. At York University (UK), Browning was involved with scanning Auger microscope and electron spectrometer design. In 1981 he joined NASA-Ames Research Center, where he concentrated on the microstructural investigation of advanced aerospace materials using scanning Auger microscopy as a primary tool. While at NASA he developed several novel techniques for the analysis of complex inhomogeneous materials using scanning Auger microscopy. He joined Stanford in 1986 to work at the Center for Integrated Systems.

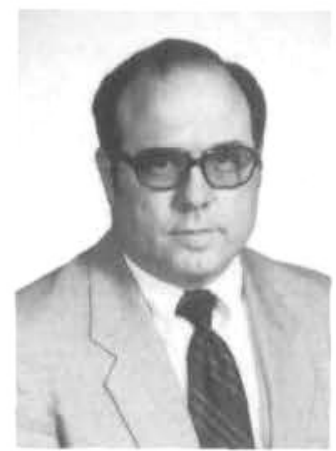

Charles E. Bryson III received his PhD in physics from the Univer. sity of MissouriRolla and a BS EE from Texas A\&M University. $\mathrm{He}$ is a fellow at the Glenn T. Seaborg Laboratory, Kevex Corporation, Foster City, CA, where his research is directed toward the application and development of analytical techniques for materials analysis. As a cofounder of Surface Science Laboratories, he was involved with the analytical applications of surface science techniques and marketing. Bryson is a member-at-large of the Applied Surface Science Division of the American Vacuum Society.

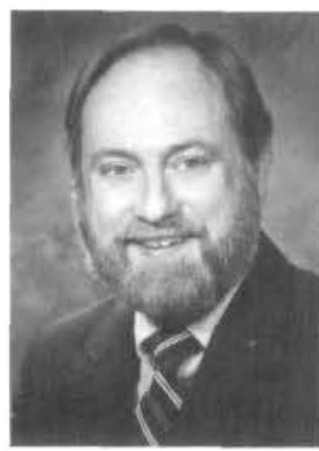

Robert Chaney is a vice president of Kevex Corporation and general manager of the Surface Science Instruments Division. He received his $\mathrm{PhD}$ in physics from the University of Washington and has a background in atomic physics, optics, biomedical instrumentation, process development, and technical manage- ment. An employee of SSI since 1979, Chaney was the project leader in charge of the X-Probe Development Program. Since its introduction, he has assumed responsibility for surface instrumentation product lines. Chaney holds patents relating to plasma light sources, spectrophotometry, molecular analysis, and respiratory gas analysis.

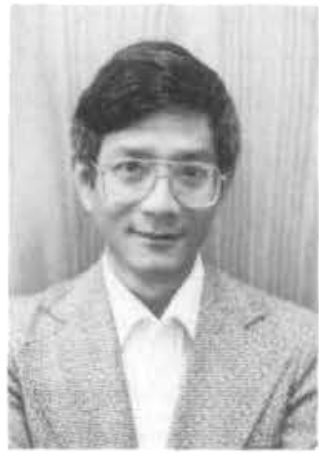

Chuan C. Chang received his BS in physics from Rensselaer Polytechnic Institute in 1962 and his $P h D$ in physics from Cornell University in 1967. He then joined Bell Telephone Laboratories, Murray Hill, NJ, as a member of the techrical staff. He has worked in the following areas: low energy electron diffraction studies of tungsten and mica surfaces, silicon-on-sapphire and silicon-onsilicon epitaxy, electrical failure analysis of CMOS circuits, and application of Auger spectroscopy, SEM, TEM, ellipsometry, SIMS, RBS, XPS, and other analytical techniques to the study of electronics materials, especially for VLSI, compound semiconductor, and photonic device fabrication. In 1983, he received the Bell Labs Distinguished Member of Technical Staff award, and joined the newly formed Bell Communications Research, Inc. In this environment, he plans to further the application of Auger and photo-electron spectroscopies to the study of materials and devices used in optical communications and computer technologies.

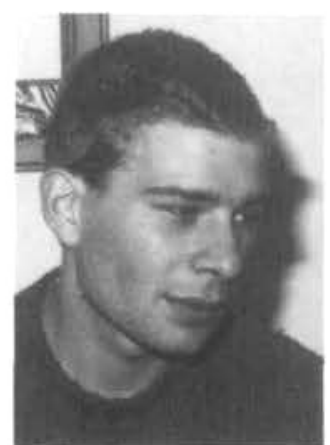

Kees Dunselman is a 1986 graduate of Utrecht State University where his studies concentrated on elastic recoil detection. Since the beginning of 1987 he has worked on the improvement of high energy ion detection tech. niques and their application to materials analysis. He is working toward his PhD in this field of research.

continued 


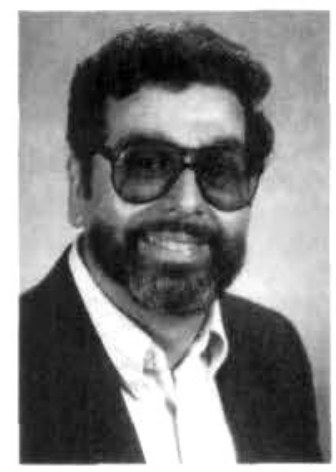

Leonard C. Feldman is head of the Thin Film Semiconductor Research Department at the Materials Processing Research Labora. tory, AT\&T Bell Laboratories, Murray Hill, $\mathrm{NJ}$. His research interests include surface structure, epitaxial growth, electronic materials and their interfaces, and the exploration of these structures using ion scattering techniques. He is the author of two books on surface and thin film analysis, editor of Applied Surface Science, initiator of surface analysis courses (Cornell University and the Materials Research Society), and a Fellow of the American Physical Society.

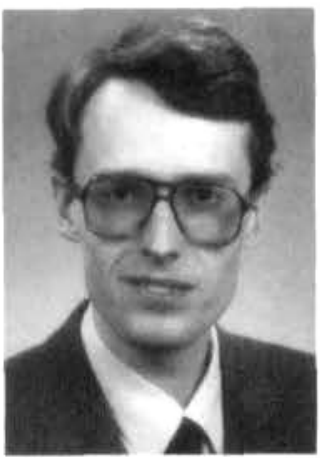

Hans-J. Gossmann is a technical staff member of the Materials Interfaces Research Group, Thin Film Semiconductor Research Depart. ment, AT\&T Bell Laboratories, Murray $\mathrm{Hill}, \mathrm{NJ}$. His research interests include fundamental aspects of epitaxial growth, such as the influence of substrate surface reconstruction and surface diffusion on the formation of an interface; the exploration of nonequilibrium structures; the use of low energy ion beams for the growth of epitaxial layers; and the investigation of these structures using ion scattering and other surface analytical techniques.

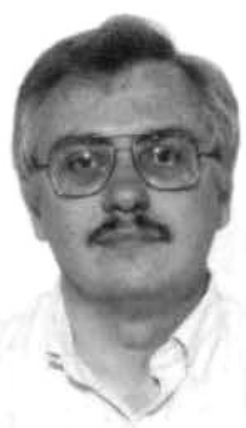

Frank J. Grunthaner is a senior research scientist in the Advanced Electronic Materials and Devices Section at the Jet Propulsion Laboratory, California Institute of Technology. Since joining JPL, his research has focused on the surface and interface chemistry of electronic materials using $x$-ray photoemission spectroscopy as a probe of local coordination geometry and structure. He has been involved in an extensive series of studies of the chemical structure of the $\mathrm{Si} /$ $\mathrm{SiO}_{2}$ interface as grown in the fabrication of MOS gate oxides. Grunthaner's interests include fundamental issues in $x$-ray photoemission from semiconductors and insulators such as the details of the chemical shift, the nature of the line shapes, and the study of heterojunction band discontinuities.

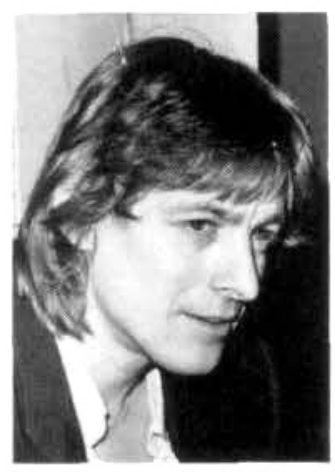

Frans Habraken obtained his PhD in 1980 , presenting a thesis on investigations in the field of surface science of metals. He then joined Philips Research Labs (Eindhoven), where he worked on the characterization of semiconductor materials. Since 1982 he has assumed responsibility for the analysis of surfaces and thin films at the Department of Atomic and Interface Physics, Utrecht State University. His main interest is the study of metal surface alloys, silicon (oxy)nitride and amorphous silicon films by using high energy ion beam methods. $\mathrm{He}$ is an author or co-author of close to 50 papers in his fields of study.

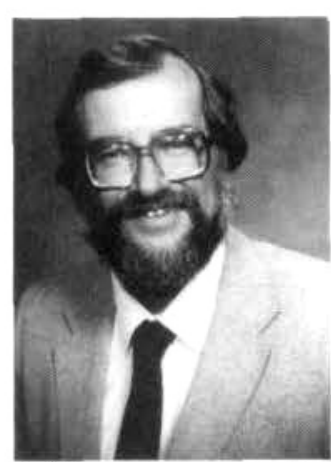

John Huneke earned his MS degree in physics in 1964 from the University of Minnesota, working with the mass spectrometry group of A.O.C. Nier in the area of rare gas isotopic studies. He continued his work at the ETH in Zurich, Switzerland, and then at the California Institute of Technology as a member of the research faculty responsible for the rare gas mass spectrometry and ion microprobe laboratories. In 1982 he left Caltech to join the staff of Charles Evans \& Associates as manager of SIMS services. Last year he became manager of the GDMS and SNMS laboratories there.

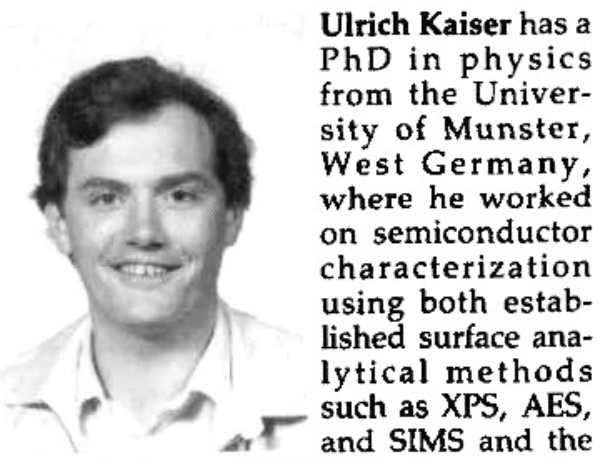
new technique of SNMS for the quantita- tive analysis of compound semiconductors. Since joining Leybold in 1985, he has worked as a project scientist in the SNMS project. He is currently doing analytical research on SNMS as a visiting scientist at Charles Evans \& Associates.

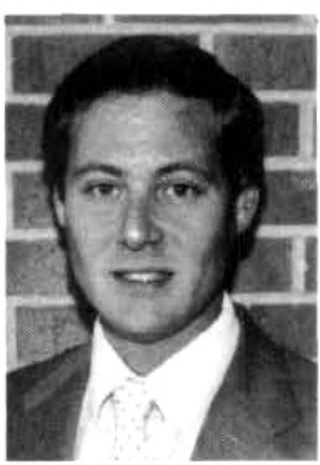

William Katz completed his graduate work at the University of Illinois where he received his MS and PhD in analytical chemistry. He also graduated from the State University of New York where he was awarded an MBA in Finance.

From 1980 to 1986 Katz worked at General Electric's Corporate R\&D Center, where he was responsible for ion beam analytical methods. During this time, he also served as adjunct professor of physics at the State University of New York. He is currently product manager of ion beam systems at the Physical Electronics Division of PerkinElmer. Katz is the author or co-author of over 60 technical papers and is listed in both Who's Who in Frontier Science and Technology and Who's Who in America.

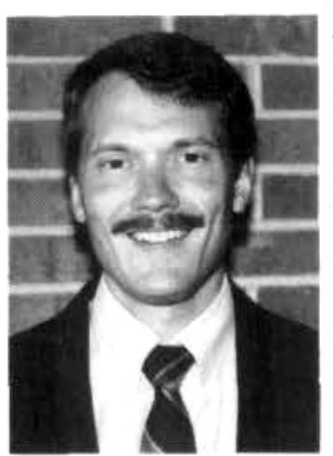

John G. Newman completed his BS degree in chemistry at Gustavus Adolphus College in 1980 and his MS degree in analytical chemistry at the University of Minnesota in 1984. His graduate work under John F. Evans involved the plasma etching and thin film analysis of polystyrene-coated electrodes. Newman joined the Analytical Lab at Physical Electronics in 1983. Since that time, he has worked as a laboratory scientist with scanning auger systems and for the past $3 \frac{1}{2}$ years has dealt exclusively with secondary ion mass spectrometry (SIMS).

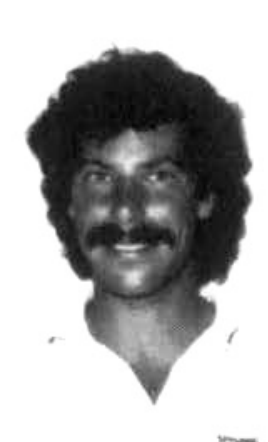

Nathan Newman has a joint appointment as a research associate at Stanford University and as a scientific staff member at Lawrence Berkeley Laboratories. He has a BS in electrical and biomedical engineering from the University of 
Southern California and an MS in electrical engineering from Stanford. He received his $\mathrm{PhD}$ in electrical engineering from Stanford University in June 1987. His research has focused on Schottky barrier diodes formed on group III-V semiconductor surfaces. He has published over 28 scientific papers.

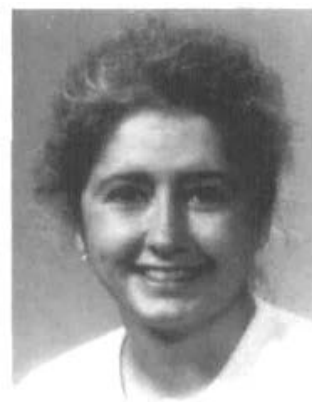

Joan B. Pallix is a postdoctoral fellow in the Chemical Physics Laboratory of SRI International. She received her $\mathrm{PhD}$ in physical chemistry from Yale University in 1986 . Her current research involves surface analysis using ion beam sputtering, multiphoton ionization and time-of-flight mass spectrometry.

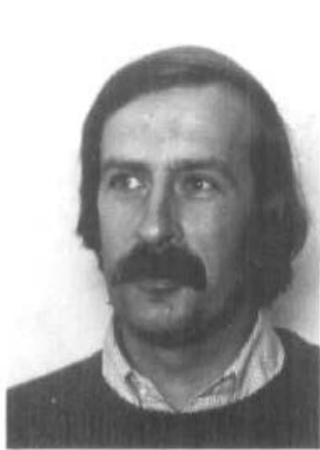

Werner van der Weg is a professor in the Department of Atomic and Interface Physics at the University of Utrecht, the Netherlands. His research interests are in surface physics, materials analysis with ion beams, and thin film amorphous silicon materials. Before joining Utrecht University he was a scientist at Philips Research Laboratories, and in that capacity spent two years involved in ion beam-solid interaction studies at the California Institute of Technology and Bell Laboratories. He has been chairman of the Dutch Vacuum Society and is presently chief editor (with L.C. Feldman) of Applied Surface Science.

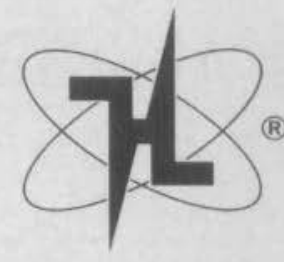

Huntington Vacuum Positioners
POSITIONING SOLUTIONS If your positioning problem cannot be solved by any of the wide range of devices already on the shelf at

Huntington, tell us about it. Whether the solution is an innovative modification or an entirely new concept,

Huntington is ready to help.

Call Huntington at 800-2278059 o: in California at 415 . 964-3323 for information on several newly patented positioning devices.

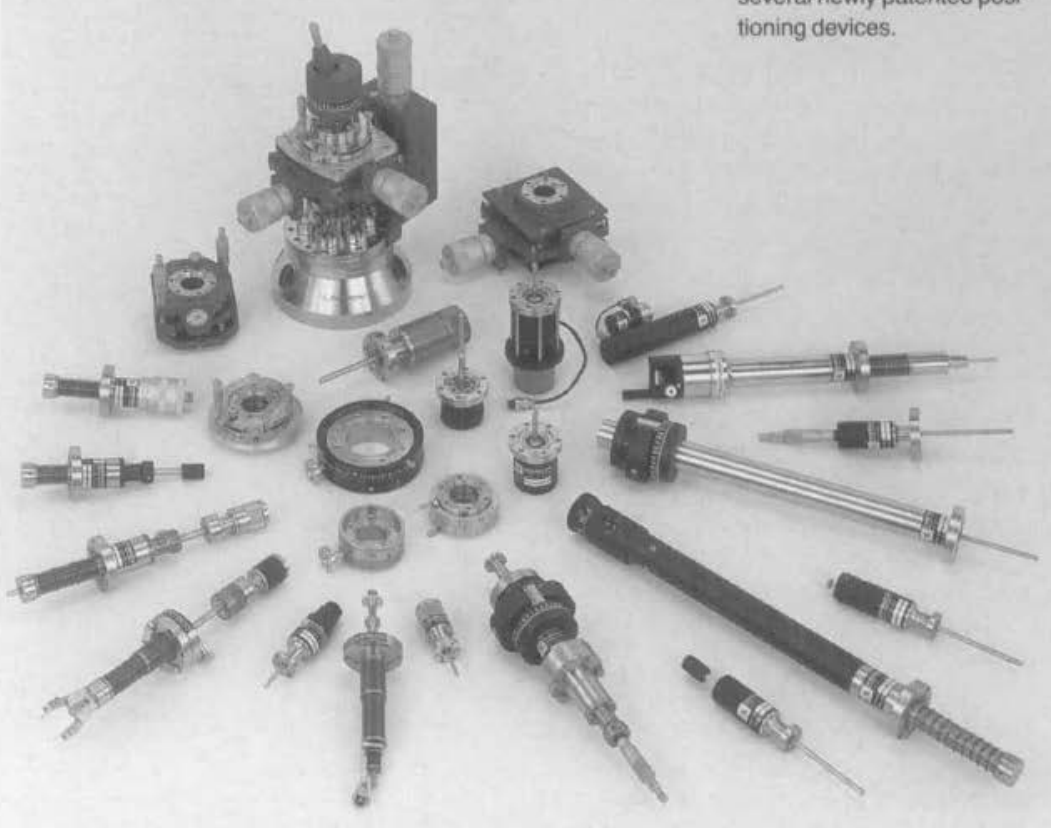

Huntington Laboratories, Inc.

1040 LAvenida, Mountain View, CA 94043 • (415) 964-3323 • (800) 227-8059

FAX (415) 964-6153 - Telex 592328 - TWX 910 379-6944 • Easylink 62-795443

Please visit Booth No. 701 at the MRS Show.

\section{Would you like to be a Guest Editor for the MRS BULLETIN?}

For information contact:

Elton N. Kaufmann, Lawrence Livermore National Laboratory, L-350, Livermore, CA 94550, telephone (415) 423-2640; or MRS headquarters, telephone (412) 367-3003 